\title{
Soluble Lectin-Like Oxidized LDL Receptor-1 and High-Sensitivity Troponin $T$ as Diagnostic Biomarkers for Acute Coronary Syndrome - Improved Values With Combination Usage in Emergency Rooms -
}

Nobuaki Kobayashi, MD; Noritake Hata, MD; Noriaki Kume, MD; Takuro Shinada, MD; Kazunori Tomita, MD; Akihiro Shirakabe, MD; Mitsunobu Kitamura, MD; Ayaka Nozaki, MD; Toru Inami; Yoshihiko Seino, MD; Kyoichi Mizuno, MD

\begin{abstract}
Background: Although highly sensitive assays for troponin T (hs-TnT) have been developed, the sensitivity and specificity of hs-TnT for diagnosing acute coronary syndrome (ACS) remains imperfect. We evaluated the diagnostic value of a new biomarker of plaque vulnerability (soluble lectin-like oxidized low-density lipoprotein receptor-1, sLOX-1) as compared with hs-TnT in the emergency room (ER).

Methods and Results: Plasma sLOX-1 and serum hs-TnT levels were measured in 200 consecutive patients presenting with chest symptoms and ECG abnormalities in the ER (116 ST elevation ACS [STEACS], 44 non-ST elevation ACS [NSTEACS], 40 non-ACS). The non-ACS group consisted of patients with cardiovascular diseases such as coronary spastic angina pectoris, pulmonary thromboembolism, perimyocarditis and takotsubo cardiomyopathy. Levels of SLOX-1 and hs-TnT were significantly higher in STEACS and NSTEACS than in non-ACS patients. The receiver-operating characteristic (ROC) curves of SLOX-1 and hs-TnT for detecting ACS, using the non-ACS patients as negative references, showed that the area under the curve (AUC) values of sLOX-1 and hs-TnT were 0.769 and 0.739 , respectively. In the lower hs-TnT $(<0.0205 \mathrm{ng} / \mathrm{ml})$ subgroup, the AUC value of the ROC curve of sLOX-1 for detecting ACS was 0.869 .
\end{abstract}

Conclusions: The diagnostic value for ACS was comparable between sLOX-1 and hs-TnT, and the accuracy of ACS diagnosis appeared to improve when sLOX-1 and hs-TnT were measured in combination. (Circ $J$ 2011; 75: 2862-2871)

Key Words: High-sensitivity troponin T; Myocardial damage; Plaque instability; Plaque rupture; Soluble lectin-like oxidized low-density lipoprotein receptor-1

A lthough acute myocardial infarction (AMI) can be diagnosed using biomarkers of myocardial necrosis or damage, such as creatine kinase-MB (CK-MB) ${ }^{1}$ and standard assay cardiac troponins, ${ }^{2-6}$ none of these is an early marker of myocardial necrosis because the elevation of these markers begins 3-4h after the onset of AMI. Highly sensitive assays for cardiac troponins have been developed ${ }^{7,8}$ and have become the gold standard for diagnosing AMI in recent years, because of improved diagnostic sensitivity for early-stage acute coronary syndrome (ACS).9,10 However, the increase in sensitivity has been associated with a decrease in specificity, ${ }^{11}$ and therefore the diagnostic sensitivity for ACS in the early stage has remained imperfect because of the optimal cut-off value. ${ }^{10}$

The specificity of highly sensitive cardiac troponins for diagnosing ACS in the real clinical setting is insufficient because these troponins are also elevated in patients with diseases other than ACS that are associated with minimal myocardial damage, such as coronary spastic angina pectoris (CSA), pulmonary thromboembolism, perimyocarditis (pericarditis and/or myocarditis) and takotsubo cardiomyopathy. It is difficult to differentiate ACS from these diseases because all of

Received July 13, 2011; revised manuscript received August 22, 2011; accepted August 23, 2011; released online September 21, 2011 Time for primary review: 19 days

Division of Intensive Care Unit (N. Kobayashi, N.H., T.S., K.T., A.S., M.K., A.N.), Department of Internal Medicine (T.I., Y.S.), Chiba Hokusoh Hospital, Nippon Medical School, Chiba; Department of Cardiovascular Medicine, Graduate School of Medicine, Kyoto University, Kyoto (N. Kume); and Division of Cardiology, Hepatology, Geriatrics and Integrated Medicine, Department of Internal Medicine, Nippon Medical School, Tokyo (K.M.), Japan

Mailing address: Nobuaki Kobayashi, MD, Intensive Care Unit, Chiba Hokusoh Hospital, Nippon Medical School, 1715 Kamagari, Inzai, Chiba 270-1694, Japan. E-mail: s5047@nms.ac.jp

ISSN-1346-9843 doi:10.1253/circj.CJ-11-0724

All rights are reserved to the Japanese Circulation Society. For permissions, please e-mail: cj@j-circ.or.jp 


\begin{tabular}{|c|c|c|c|c|}
\hline & \multicolumn{2}{|c|}{ ACS } & \multirow{2}{*}{ Non-ACS $(n=40)$} & \multirow{2}{*}{$P$ value } \\
\hline & STEACS $(n=116)$ & NSTEACS $(n=44)$ & & \\
\hline Male, $\mathrm{n}(\%)$ & $105(91)^{*, \dagger}$ & $30(68)^{*}$ & $25(63)^{\dagger}$ & $<0.001$ \\
\hline Age (years), mean $\pm S D$ & $64 \pm 12$ & $66 \pm 10$ & $66 \pm 13$ & 0.700 \\
\hline \multicolumn{5}{|l|}{ Risk factors, n (\%) } \\
\hline Diabetes & $40(34)^{\ddagger}$ & $11(25)^{\S}$ & $3(8)^{\ddagger \S}$ & 0.004 \\
\hline Hypertension & $71(61)^{\#}$ & $34(77)^{\ddagger \ddagger}$ & $15(38)^{\#, \neq \neq}$ & $<0.001$ \\
\hline Dyslipidemia & $74(64)$ & $29(66)$ & $20(50)$ & 0.240 \\
\hline Smoking & $75(65)^{\Uparrow}$ & $21(48)$ & $14(35)^{\Uparrow}$ & 0.003 \\
\hline \multicolumn{5}{|l|}{ Prehospital drug use } \\
\hline ACEI/ARB & $21(18)$ & $6(14)$ & $4(10)$ & 0.440 \\
\hline Statin & $9(8)$ & $8(18)$ & $4(10)$ & 0.188 \\
\hline Creatinine $(\mathrm{mg} / \mathrm{dl})$, mean $\pm \mathrm{SD}$ & $0.90 \pm 0.28$ & $0.91 \pm 0.48$ & $0.83 \pm 0.27$ & 0.389 \\
\hline Peak CK-MB (IU/L), median ( $25-75^{\text {th }}$ percentiles) & $124(66-228)$ & $18(11-40)$ & $7(5-10)$ & $<0.001$ \\
\hline $\begin{array}{l}\text { Interval from the onset of symptoms to ER arrival (min), median } \\
\left(25-75^{\text {th }} \text { percentiles) }\right.\end{array}$ & $\begin{array}{l}146 \\
(82-416)^{\star *,+\dagger}\end{array}$ & $\begin{array}{c}296 \\
(125-900)^{\star \star}\end{array}$ & $\begin{array}{l}310 \\
(105-1,145)^{\dagger \dagger}\end{array}$ & 0.010 \\
\hline \multicolumn{5}{|l|}{ Culprit vessel } \\
\hline Right coronary artery, $\mathrm{n}(\%)$ & $44(38)$ & $9(20)$ & & 0.036 \\
\hline Left anterior descending artery, $\mathrm{n}(\%)$ & $62(53)$ & $26(59)$ & & 0.522 \\
\hline Left circumflex artery, n (\%) & $10(9)$ & $9(20)$ & & 0.039 \\
\hline No. of diseased vessels, mean \pm SD & $1.76 \pm 0.81$ & $1.71 \pm 0.77$ & & 0.539 \\
\hline
\end{tabular}

By the $\chi^{2}$ test: ${ }^{*} \mathrm{P}<0.001$ between STEACS and NSTEACS; ${ }^{\mathrm{P}}<0.001$ between $S T E A C S$ and non-ACS; $\neq \mathrm{P}=0.001$ between $S T E A C S$ and non-

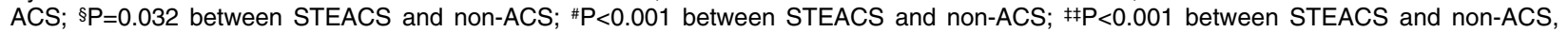
१P $=0.001$ between STEACS and non-ACS.

By the Mann Whitney $U$ test: ${ }^{* *} \mathrm{P}=0.013$ between STEACS and NSTEACS. ${ }^{\mathrm{t} P} \mathrm{P}=0.019$ between STEACS and non-ACS.

ACS, acute coronary syndrome; STEACS, ST elevation acute coronary syndrome; NSTEACS, non-STE acute coronary syndrome; ACEI, angiotensin-converting enzyme inhibitor; ARB, angiotensin-receptor blocker; CK, creatine kinase; ER, emergency room.

them exhibit similar chest symptoms and ECG abnormalities, as well as subtle increases in biomarkers for cardiac damage. In fact, the usefulness of cardiac biomarkers for these differential diagnoses has not been fully reported yet.

Lectin-like oxidized low-density lipoprotein (LDL) receptor-1 (LOX-1) is a receptor for atherogenic oxidized LDL, which is abundantly expressed in advanced human atherosclerotic plaques. ${ }^{12}$ It is cleaved at the membrane-proximal extracellular domain by proteases, and released as a soluble form. ${ }^{13,14}$ Therefore, soluble LOX-1 (sLOX-1) is regarded as a marker of plaque rupture or instability. Our previous studies revealed the diagnostic value of sLOX-1 for early-stage ACS in which conventional troponin $\mathrm{T}$ ( $\mathrm{TnT}$ ) was unable to provide a diagnosis. ${ }^{13,15-19}$ However, the diagnostic value of sLOX-1 has not been compared with the highly sensitive form of TnT (hs-TnT) in the emergency room (ER), where ACS needs to be distinguished from non-ACS with similar acute chest symptoms and ECG abnormalities.

The aim of the present study was to evaluate the diagnostic value of sLOX-1 and hs-TnT for patients in the ER with chest symptoms suggestive of ACS and ECG abnormalities.

\section{Methods}

\section{Study Population}

Between April 2008 and December 2009 we assigned 200 consecutive patients (160 males, 40 females; mean age, $65 \pm 12$ years) presenting at the ER of Nippon Medical School Chiba Hokusoh Hospital with chest symptoms and ECG abnormalities within $48 \mathrm{~h}$ of the onset of chest symptoms, which were defined as chest pain, chest oppression and chest discomfort suggestive of ACS. ECG abnormalities were defined as ST segment elevation or depression $(\geq 0.05 \mathrm{mV})$, and/or T wave inversion $(\geq 0.05 \mathrm{mV})$, in 2 or more contiguous leads on the ECG. ACS was defined as prolonged chest pain ( $\geq 20 \mathrm{~min}$ ) with a coronary artery lesion on coronary angiography. STEACS and NSTEACS were respectively defined as ACS with and without ST segment elevation $(\geq 0.05 \mathrm{mV})$ in 2 or more contiguous leads on ECG. ACS, STEACS and NSTEACS within $3 \mathrm{~h}$ of the onset of chest symptoms were all defined as "early". Patients undergoing renal replacement therapy for either acute or chronic kidney disease, and those on a percutaneous cardiopulmonary support system for cardiogenic shock or fatal arrhythmia were excluded from the study.

\section{Measurement of SLOX-1 and hs-TnT}

Sampling Methods and Biomarker Measurements Peripheral blood samples were obtained in the ER, and the plasma samples were separated by centrifugation and stored frozen at $-80^{\circ} \mathrm{C}$. Plasma sLOX-1 levels were measured using a sandwich chemiluminescent enzyme immunoassay (CLEIA) with 2 newly-developed anti-human LOX-1 monoclonal antibodies, ${ }^{17}$ which a modification of a previously described enzyme-linked immunosorbent assay (ELISA) using the former polyclonal antibodies. ${ }^{16}$ Intra- and interassay coefficients of variation (CV) were reported to be $4.4-6.5 \%$ and $4.0-6.1 \%$, respectively, and the lower limit of detection for SLOX-1 was $8.0 \mathrm{pg} / \mathrm{ml} .{ }^{17}$ Serum hs-TnT levels were measured using an electrochemoluminescence immunoassay (ECLusys Troponin hs; Roche Diagnostics $\mathrm{Co}$, Tokyo, Japan). Intra- and interassay $\mathrm{CVs}$ were reported to be $0.5-5.7 \%$ and $1.4-3.0 \% \mathrm{ng} / \mathrm{ml}$, respectively, and the lower limit of the detection for hs-TnT was $0.003 \mathrm{ng} / \mathrm{ml} .^{20}$

\section{Statistical Analysis}

Continuous variables are presented as means \pm standard deviation and were compared between 2 groups by Student's t-test 

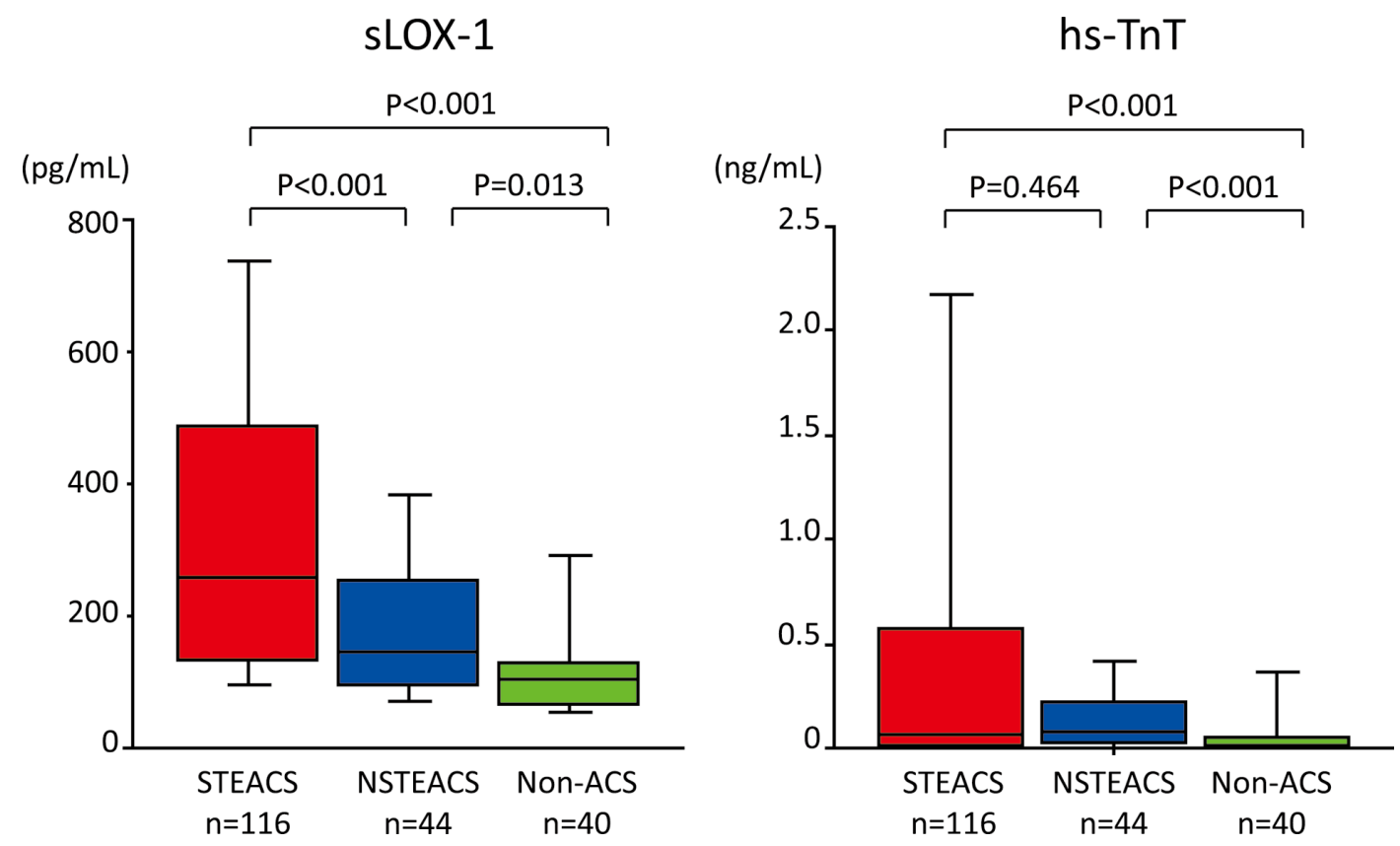

Figure 1. Plasma levels of soluble lectin-like oxidized low-density lipoprotein receptor-1 (sLOX-1) and serum high-sensitivity troponin T (hs-TnT) were compared in consecutive patients with chest symptoms and ECG abnormalities in the emergency room among groups of patients with ST elevation acute coronary syndrome (STEACS, $n=116$ ), non-STE ACS (NSTEACS, $n=44$ ) and non-ACS, $n=44)$. Center horizontal lines indicate median values. Lower and upper edges of boxes indicate $25^{\text {th }}$ and $75^{\text {th }}$ percentiles, and lower and upper bars indicate $10^{\text {th }}$ and $90^{\text {th }}$ percentiles, respectively.

and among 3 groups by 1-way ANOVA. Dichotomous variables were compared using $\chi^{2}$ statistics. Because sLOX-1, hs-TnT, CK-MB and time intervals were not normally distributed, these values are presented as medians and $25^{\text {th }}$ and $75^{\text {th }}$ percentiles, and were compared by Mann Whitney U test and Kruskal-Wallis test for 2 and 3 groups, respectively. The correlation of the plasma SLOX-1 or serum hs-TnT level in the ER with the time interval from the onset of chest symptoms to ER arrival was analyzed by Spearman's rank correlation test. To compare the sensitivities and specificities of sLOX-1 and hs-TnT for diagnosing ACS, receiver-operating characteristics (ROC) curve analyses were carried out using the non-ACS subjects as negative controls. ACS patients whose SLOX-1 and hs-TnT values were less than the optimal cut-off values determined from the ROC curves to diagnose ACS were defined as the sLOX-1-negative ACS subgroup and hs-TnT-negative ACS subgroup, respectively. ACS patients whose SLOX-1 and hs-TnT values were more than those optimal cut-off values, were defined as sLOX-1-positive ACS subgroup and hs-TnT positive ACS subgroup, respectively. Data were statistically analyzed using the SPSS software package, version 16.0. A P-value $<0.05$ was considered statistically significant. The Ethics Committee of the hospital approved the study protocols, and written informed consent to participate in the investigations was given by all of the patients.

\section{Results}

\section{Characteristics of the Enrolled Patients}

The 200 consecutive patients enrolled in this study consisted of 160 patients with ACS (116 STEACS, 44 NSTEACS) and 40 patients with non-ACS (23 CSA, 6 arrhythmia, 6 pulmo- nary thromboembolism, 3 perimyocarditis, 2 takotsubo cardiomyopathy). Their characteristics are shown in Table 1. Age, prevalence of dyslipidemia, and serum creatinine levels were comparable among the STEACS, NSTEACS and non-ACS groups. Prevalence of prehospital use of angiotensin-converting inhibitors (ACEI)/angiotensin-receptor blockers (ARB), and statins was also comparable among the 3 groups. Risk factors, including diabetes, hypertension and smoking habit, were comparable between the STEACS and NSTEACS groups, but were more prevalent in patients with ACS than in the non-ACS group. Males were more prevalent in the STEACS group than in the NSTEACS and non-ACS groups. Peak serum CK-MB levels were significantly higher in the STEACS and NSTEACS groups than in the non-ACS group $(\mathrm{P}<0.001)$, and significantly higher in the STEACS group than in the NSTEACS group $(\mathrm{P}<0.001)$. The time interval from the onset of chest symptoms to ER arrival was significantly shorter in the STEACS group than in the NSTEACS $(\mathrm{P}=0.013)$ and non-ACS $(\mathrm{P}=$ $0.019)$ groups. The time intervals was comparable between the NSTEACS and non-ACS groups $(\mathrm{P}=0.914)$. Concerning the culprit vessel in ACS, the incidence of left anterior descending artery lesions was comparable between the STEACS and NSTEACS groups; however, right coronary artery lesions were more prevalent in the STEACS group, and left circumflex lesions were more prevalent in the NSTEACS group. The number of diseased vessels was comparable between the 2 ACS groups.

\section{Comparison of sLOX-1 and hs-TnT Levels}

As shown in Figure 1, the median and $25^{\text {th }}$ and $75^{\text {th }}$ percentile values of plasma sLOX-1 were $259.0,134.5$ and $488.9 \mathrm{pg} / \mathrm{ml}$ for STEACS, 143.9, 96.6 and $255.1 \mathrm{pg} / \mathrm{ml}$ for NSTEACS, and 


\begin{tabular}{|c|c|c|c|c|c|}
\hline & $\mathbf{n}$ & $\begin{array}{c}\text { sLOX-1 }(\mathrm{pg} / \mathrm{ml}) \\
\text { median }\left(25-75^{\text {th }} \text { percentiles }\right)\end{array}$ & $P$ value & $\begin{array}{c}\text { hs-TnT }(\mathrm{ng} / \mathrm{ml}) \\
\text { median }\left(25-75^{\text {th }} \text { percentiles }\right)\end{array}$ & $P$ value \\
\hline \multicolumn{6}{|l|}{ Gender } \\
\hline Male & 160 & $176.6(103.3-403.0)$ & \multirow{2}{*}{0.153} & $0.050(0.010-0.259)$ & \multirow{2}{*}{0.586} \\
\hline Female & 40 & $151.9(100.2-288.3)$ & & $0.058(0.008-0.508)$ & \\
\hline \multicolumn{6}{|l|}{ Diabetes } \\
\hline$(+)$ & 54 & $264.9(167.5-402.5)$ & \multirow{2}{*}{0.008} & $0.080(0.017-0.252)$ & \multirow{2}{*}{0.220} \\
\hline$(-)$ & 146 & $147.3(96.1-361.3)$ & & $0.040(0.008-0.330)$ & \\
\hline \multicolumn{6}{|c|}{ Hypertension } \\
\hline$(+)$ & 120 & $174.6(108.5-398.2)$ & \multirow{2}{*}{0.242} & $0.055(0.014-0.278)$ & \multirow{2}{*}{0.475} \\
\hline$(-)$ & 80 & $158.3(91.2-362.9)$ & & $0.046(0.008-0.325)$ & \\
\hline \multicolumn{6}{|c|}{ Dyslipidemia } \\
\hline$(+)$ & 123 & $174.5(106.7-359.4)$ & \multirow{2}{*}{0.468} & $0.058(0.008-0.270)$ & \multirow{2}{*}{0.699} \\
\hline$(-)$ & 77 & $150.7(94.5-402.8)$ & & $0.049(0.012-0.340)$ & \\
\hline \multicolumn{6}{|l|}{ Smoking } \\
\hline$(+)$ & 110 & $218.7(118.3-402.5)$ & \multirow{2}{*}{0.012} & $0.042(0.010-0.271)$ & \multirow{2}{*}{0.626} \\
\hline$(-)$ & 90 & $130.1(93.6-317.6)$ & & $0.055(0.010-0.350)$ & \\
\hline \multicolumn{6}{|l|}{ ACEI/ARB } \\
\hline$(+)$ & 31 & $156.8(99.6-362.1)$ & \multirow{2}{*}{0.082} & $0.050(0.016-0.136)$ & \multirow{2}{*}{0.903} \\
\hline$(-)$ & 169 & $281.8(130.2-434.8)$ & & $0.050(0.009-0.333)$ & \\
\hline \multicolumn{6}{|l|}{ Statin } \\
\hline$(+)$ & 21 & $252.0(169.6-411.3)$ & \multirow{2}{*}{0.559} & $0.035(0.017-0.141)$ & \multirow{2}{*}{0.559} \\
\hline$(-)$ & 179 & $155.5(99.4-367.5)$ & & $0.054(0.010-0.338)$ & \\
\hline
\end{tabular}

sLOX-1, soluble lectin-like oxidized LDL receptor-1; hs-TnT, high-sensitivity troponin T. Other abbreviations see in Table 1.
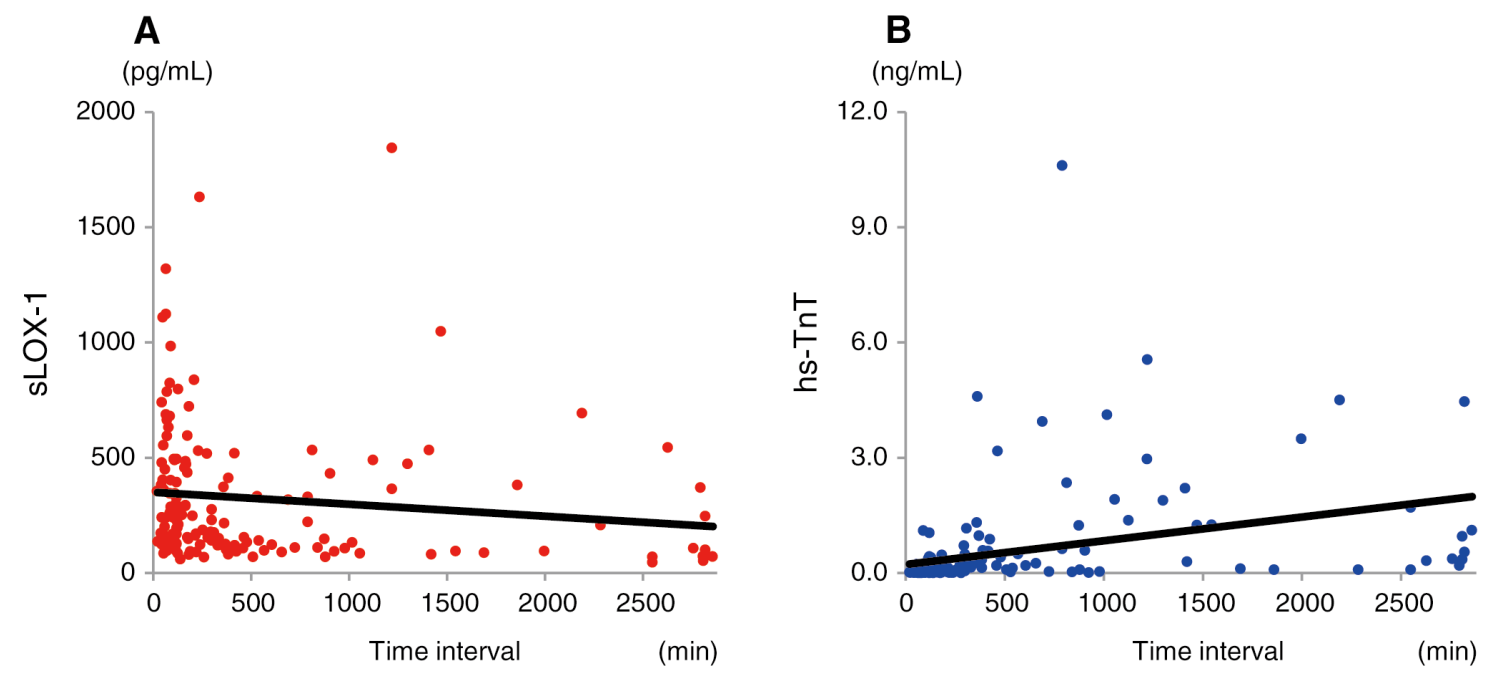

Figure 2. (A) Plasma soluble lectin-like oxidized low-density lipoprotein receptor-1 (sLOX-1) levels inversely correlate with the time interval from the onset of chest symptoms to emergency room arrival (Spearman $\rho=-0.313, P<0.001$ ). (B) Serum high-sensitivity troponin $\mathrm{T}$ (hs-TnT) levels positively correlate with the time interval (Spearman $\rho=0.639, P<0.001$ ).

104.1, 67.9 and $128.6 \mathrm{pg} / \mathrm{ml}$ for non-ACS, respectively. Plasma sLOX-1 levels were significantly higher in the STEACS $(\mathrm{P}<$ $0.001)$ and NSTEACS $(\mathrm{P}=0.013)$ groups than in the non-ACS group, and were significantly more elevated in the STEACS group $(\mathrm{P}<0.001)$ than in the NSTEACS group. The respective values of serum hs-TnT for STEACS were $0.060,0.016$ and $0.569 \mathrm{ng} / \mathrm{ml}, 0.050,0.020$ and $0.217 \mathrm{ng} / \mathrm{ml}$ for NSTEACS, and $0.008,0.004$ and $0.050 \mathrm{ng} / \mathrm{ml}$ for non-ACS. Serum hs-TnT levels were significantly higher in the STEACS $(\mathrm{P}<0.001)$ and NSTEACS $(\mathrm{P}<0.001)$ groups than in the non-ACS group. Serum hs-TnT levels were comparable between the STEACS and NSTEACS $(\mathrm{P}=0.464)$ patients.

Table 2 shows that plasma sLOX-1, but not serum hs-TnT, levels were significantly higher in patients with diabetes or a smoking habit than those without. Neither hypertension, sex, nor prehospital use of ACEI/ARB or statins significantly 

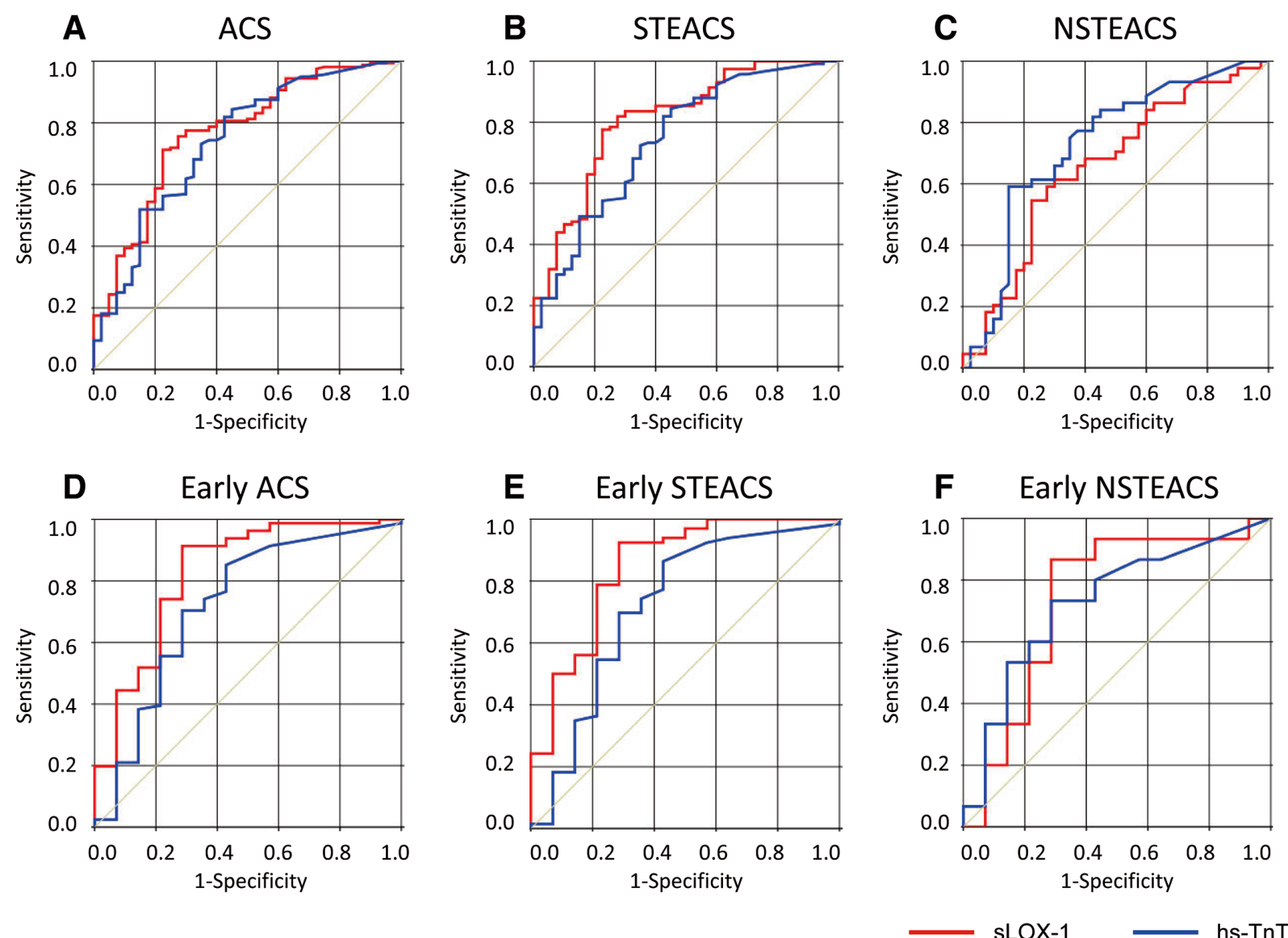

Figure 3. Receiver-operating characteristic curves for diagnostic sensitivity and specificity of soluble lectin-like oxidized lowdensity lipoprotein receptor-1 (sLOX-1) and high-sensitivity troponin T (hs-TnT) for diagnosing (A) acute coronary syndrome (ACS), (B) ST elevation ACS (STEACS), (C) non-STE ACS (NSTEACS), (D) early ACS, (E) early STEACS and (F) early NSTEACS. The area under the curve values for SLOX-1 and hs-TnT were 0.769 and 0.739 for ACS, 0.818 and 0.743 for STEACS, and 0.658 and 0.729 for NSTEACS, 0.826 and 0.722 for early ACS, 0.846 and 0.720 for early STEACS, and 0.738 and 0.729 for early NSTEACS, respectively. Early ACS was defined as ACS within $3 \mathrm{~h}$ of onset.

affected the plasma sLOX-1 or serum hs-TnT level (Table 2). Plasma sLOX-1 levels were significantly and inversely correlated with the time interval from the onset of chest symptoms to ER arrival (Figure 2A; Spearman $\rho=-0.313, \mathrm{P}<0.001$ ). In contrast, serum hs-TnT levels were significantly and positively correlated with this interval (Figure 2B; Spearman $\rho=$ $0.639, \mathrm{P}<0.001)$.

\section{Diagnostic Value of sLOX-1 and hs-TnT for ACS}

To evaluate the diagnostic accuracy of SLOX-1 and hs-TnT for ACS, STEACS and NSTEACS, their levels were compared between ACS and non-ACS patients, as well as among the STEACS, NSTEACS and non-ACS groups. The ROC curves of sLOX-1 and hs-TnT for detecting ACS, STEACS and NSTEACS using the non-ACS group as a negative reference are shown in Figures $\mathbf{3 A}-\mathbf{C}$ and the diagnostic accuracy determined by these ROC curves is indicated in Table 3 . The area under the curve (AUC) values of these ROC curves for sLOX-1 and hs-TnT to diagnose ACS were 0.769 and 0.739 , respectively. The sensitivity and specificity of SLOX-1 to diagnose ACS were $71.2 \%$ and $77.5 \%$, respectively, at an optimal cut-off value of $131.7 \mathrm{pg} / \mathrm{ml}$, and those of hs-TnT were
$73.1 \%$ and $65.0 \%$, respectively, at an optimal cut-off value of $0.0205 \mathrm{ng} / \mathrm{ml}$.

Comparing the Diagnostic Value of sLOX-1 and hs-TnT for Early Stage of ACS (Within $3 \mathrm{~h}$ of the Onset of Symptoms)

The ROC curves of sLOX-1 and hs-TnT for detecting the early stage of ACS, STEACS and NSTEACS, using the early nonACS group as a negative reference, are shown in Figures 3DF and the diagnostic accuracy determined by these ROC curves is indicated in Table 3 . The ROC curves indicated that the AUC values for sLOX-1 and hs-TnT to diagnose early ACS were 0.826 and 0.722 , respectively. The sensitivity and specificity of sLOX-1 to diagnose early ACS were $91.4 \%$ and $71.4 \%$, respectively, at an optimal cut-off value of $116.2 \mathrm{pg} / \mathrm{ml}$, and those for hs-TnT were $70.4 \%$ and $71.4 \%$, respectively, at an optimal cut-off value of $0.0109 \mathrm{ng} / \mathrm{ml}$.

\section{Evaluating the Diagnostic Value of sLOX-1 for ACS} in Patients With hs-TnT-Negative ACS

ACS patients whose hs-TnT values were less than $0.0205 \mathrm{ng} / \mathrm{ml}$, which was the optimal cut-off value determined from the ROC curve to diagnose ACS (Figure 3A), were defined as 


\begin{tabular}{|c|c|c|c|c|c|}
\hline & AUC & Cut-off value & $\begin{array}{c}\text { Sensitivity } \\
(\%)\end{array}$ & $\begin{array}{c}\text { Specificity } \\
(\%)\end{array}$ & $P$ value \\
\hline \multicolumn{6}{|c|}{ To diagnose all ACS } \\
\hline sLOX-1 & 0.769 & $131.7 \mathrm{pg} / \mathrm{ml}$ & 71.2 & 77.5 & $<0.001$ \\
\hline hs-TnT & 0.739 & $0.0205 \mathrm{ng} / \mathrm{ml}$ & 73.1 & 65.0 & $<0.001$ \\
\hline \multicolumn{6}{|c|}{ To diagnose STEACS } \\
\hline sLOX-1 & 0.811 & $131.7 \mathrm{pg} / \mathrm{ml}$ & 77.6 & 77.5 & $<0.001$ \\
\hline hs-TnT & 0.743 & $0.0210 \mathrm{ng} / \mathrm{ml}$ & 72.4 & 65.0 & $<0.001$ \\
\hline \multicolumn{6}{|c|}{ To diagnose NSTEACS } \\
\hline sLOX-1 & 0.658 & $136.1 \mathrm{pg} / \mathrm{ml}$ & 54.5 & 77.5 & 0.013 \\
\hline hs-TnT & 0.729 & $0.0205 \mathrm{ng} / \mathrm{ml}$ & 75.0 & 65.0 & $<0.001$ \\
\hline \multicolumn{6}{|c|}{ To diagnose all early ACS } \\
\hline sLOX-1 & 0.826 & $116.2 \mathrm{pg} / \mathrm{ml}$ & 91.4 & 71.4 & $<0.001$ \\
\hline hs-TnT & 0.722 & $0.0109 \mathrm{ng} / \mathrm{ml}$ & 70.4 & 71.4 & 0.008 \\
\hline \multicolumn{6}{|c|}{ To diagnose early STEACS } \\
\hline sLOX-1 & 0.846 & $116.2 \mathrm{pg} / \mathrm{ml}$ & 92.4 & 71.4 & $<0.001$ \\
\hline hs-TnT & 0.720 & $0.0114 \mathrm{ng} / \mathrm{ml}$ & 69.7 & 71.4 & 0.010 \\
\hline \multicolumn{6}{|c|}{ To diagnose early NSTEACS } \\
\hline sLOX-1 & 0.738 & $119.0 \mathrm{pg} / \mathrm{ml}$ & 86.7 & 71.4 & 0.029 \\
\hline hs-TnT & 0.729 & $0.0109 \mathrm{ng} / \mathrm{ml}$ & 73.3 & 71.4 & 0.036 \\
\hline \multicolumn{6}{|c|}{ To diagnose ACS in hs-TnT negative ACS } \\
\hline sLOX-1 & 0.869 & $116.2 \mathrm{pg} / \mathrm{ml}$ & 90.7 & 80.8 & $<0.001$ \\
\hline \multicolumn{6}{|c|}{ To diagnose STEACS in hs-TnT negative ACS } \\
\hline sLOX-1 & 0.898 & $116.2 \mathrm{pg} / \mathrm{ml}$ & 90.3 & 80.8 & $<0.001$ \\
\hline \multicolumn{6}{|c|}{ To diagnose NSTEACS in hs-TnT negative ACS } \\
\hline sLOX-1 & 0.783 & $118.1 \mathrm{pg} / \mathrm{ml}$ & 81.8 & 80.8 & 0.007 \\
\hline \multicolumn{6}{|c|}{ To diagnose ACS in sLOX-1 negative ACS } \\
\hline hs-TnT & 0.798 & $0.0520 \mathrm{pg} / \mathrm{ml}$ & 73.9 & 83.9 & $<0.001$ \\
\hline \multicolumn{6}{|c|}{ To diagnose STEACS in sLOX-1 negative ACS } \\
\hline hs-TnT & 0.825 & $0.0550 \mathrm{pg} / \mathrm{ml}$ & 76.9 & 83.9 & $<0.001$ \\
\hline \multicolumn{6}{|c|}{ To diagnose NSTEACS in sLOX-1 negative ACS } \\
\hline hs-TnT & 0.764 & $0.0205 \mathrm{pg} / \mathrm{ml}$ & 80.0 & 71.0 & 0.002 \\
\hline
\end{tabular}

ROC, receiver-operating characteristics; AUC, area under the curve. Other abbreviations see in Tables 1,2.

the hs-TnT-negative ACS subgroup, and those with hs-TnT more than $0.0205 \mathrm{ng} / \mathrm{ml}$ were defined as the hs-TnT-positive ACS subgroup. The characteristics of both these subgroups are summarized in Table 4. Sex and the prevalence of coronary risk factors, such as diabetes, hypertension, dyslipidemia and smoking, and prevalence of STEACS, were comparable between these subgroups, except that subjects were younger in the hs-TnT-negative ACS subgroup. Plasma sLOX-1 levels were significantly higher $(\mathrm{P}=0.034)$ in the hs-TnT-negative ACS subgroup (median, $25^{\text {th }}$ and $75^{\text {th }}$ percentiles: $269.7,150.0$ and $520.3 \mathrm{pg} / \mathrm{ml}$, respectively) than in the hs-TnT-positive ACS subgroup (median, $25^{\text {th }}$ and $75^{\text {th }}$ percentiles: $199.5,107.3$ and $374.7 \mathrm{pg} / \mathrm{ml}$, respectively). Serum creatinine levels were significantly higher in the hs-TnT-negative ACS subgroup than in the hs-TnT-positive ACS subgroup ( $\mathrm{P}=0.027)$. Peak CK-MB levels were comparable between these subgroups.

Time intervals from the onset of chest symptoms to ER arrival were significantly shorter $(\mathrm{P}<0.001)$ in the hs-TnTnegative ACS subgroup (median, $25^{\text {th }}$ and $75^{\text {th }}$ percentiles: 90 , 65 and $136 \mathrm{~min}$, respectively) than in the hs-TnT-positive ACS subgroup (median, 25 th and $75^{\text {th }}$ percentiles: 300, 119 and 849 min, respectively). The ROC curves of sLOX-1 for detecting ACS, STEACS and NSTEACS in the respective hs-TnTnegative subgroups, using the hs-TnT-negative non-ACS subgroup as a negative reference, are shown in Figures $4 \mathrm{~A}-\mathrm{C}$ and the diagnostic accuracy determined by these ROC curves is indicated in Table 3. The AUC values of these ROC curves for sLOX-1 were $0.869,0.898$, and 0.783 , to detect ACS, STEACS and NSTEACS, respectively, and the sensitivity and specificity of sLOX-1 to diagnose ACS in the patients with negative hs-TnT ACS were $90.7 \%$ and $80.8 \%$, respectively, at the optimal cut-off value of $116.2 \mathrm{pg} / \mathrm{ml}$.

\section{Evaluating the Diagnostic Value of hs-TnT for ACS in Patients With sLOX-1-Negative ACS}

Similarly, ACS patients whose sLOX-1 values were less than $131.7 \mathrm{pg} / \mathrm{ml}$, which was the cut-off value determined from the ROC curve to diagnose ACS (Figure 3A), were defined as the sLOX-1-negative ACS subgroup, and those with sLOX-1 more than $131.7 \mathrm{pg} / \mathrm{ml}$ were defined as the sLOX-1-positive ACS subgroup. Sex and the prevalence of coronary risk factors, such as diabetes, hypertension and dyslipidemia, were comparable between these subgroups, except that smokers were more prevalent in the sLOX-1-positive ACS subgroup. In addition, patients with STEACS were more prevalent in the sLOX-1-positive ACS subgroup. Serum hs-TnT and creatinine levels were comparable between these subgroups. Peak serum CK-MB levels were higher in the positive sLOX-1 ACS subgroup than in the negative sLOX-1 ACS subgroup.

Time intervals from the onset of chest symptoms onset to ER 


\begin{tabular}{|c|c|c|c|c|c|c|}
\hline & $\begin{array}{c}\text { hs-TnT-negative } \\
\text { ACS } \\
\text { (hs-TnT <0.0205) } \\
(n=43)\end{array}$ & $\begin{array}{c}\text { hs-TnT-positive } \\
\text { ACS } \\
\text { (hs-TnT } \geq 0.0205) \\
(n=117)\end{array}$ & $P$ value & $\begin{array}{c}\text { sLOX-1-negative } \\
\text { ACS } \\
\text { (sLOX-1 <131.7) } \\
(n=46)\end{array}$ & $\begin{array}{c}\text { sLOX-1-positive } \\
\text { ACS } \\
\text { (sLOX-1 } \geq 131.7) \\
(n=114)\end{array}$ & $P$ value \\
\hline Male, n (\%) & $39(91)$ & $96(82)$ & 0.182 & $38(83)$ & $97(85)$ & 0.696 \\
\hline Age (years), mean $\pm S D$ & $61 \pm 10$ & $66 \pm 11$ & 0.014 & $64 \pm 11$ & $65 \pm 11$ & 0.836 \\
\hline \multicolumn{7}{|l|}{ Risk factors, n (\%) } \\
\hline Diabetes & $15(35)$ & $36(31)$ & 0.621 & $11(24)$ & $40(35)$ & 0.170 \\
\hline Hypertension & $31(72)$ & $74(63)$ & 0.296 & $29(63)$ & $76(67)$ & 0.662 \\
\hline Dyslipidemia & $29(67)$ & $74(63)$ & 0.623 & $26(57)$ & $77(68)$ & 0.188 \\
\hline Smoking & $29(67)$ & $67(57)$ & 0.244 & $21(46)$ & $75(66)$ & 0.019 \\
\hline STEACS, n (\%) & $32(74)$ & $84(71)$ & 0.742 & $26(57)$ & $90(79)$ & 0.004 \\
\hline $\begin{array}{l}\text { sLOX-1 }(\mathrm{pg} / \mathrm{ml}), \text { median } \\
\left(25-75^{\text {th }} \text { percentiles }\right)\end{array}$ & $\begin{array}{c}269.7 \\
(150.0-520.3)\end{array}$ & $\begin{array}{c}199.5 \\
(107.3-374.7)\end{array}$ & 0.034 & $\begin{array}{c}94.4 \\
(80.6-109.5)\end{array}$ & $\begin{array}{c}327.5 \\
(192.8-493.6)\end{array}$ & $<0.001$ \\
\hline $\begin{array}{l}\text { hs-TnT (ng/ml), median } \\
\left(25-75^{\text {th }} \text { percentiles }\right)\end{array}$ & $\begin{array}{c}0.007 \\
(0.005-0.013)\end{array}$ & $\begin{array}{c}0.178 \\
(0.059-0.580)\end{array}$ & $<0.001$ & $\begin{array}{c}0.138 \\
(0.032-0.490)\end{array}$ & $\begin{array}{c}0.050 \\
(0.014-0.320)\end{array}$ & 0.093 \\
\hline Creatinine $(\mathrm{mg} / \mathrm{dl})$, mean $\pm \mathrm{SD}$ & $0.81 \pm 0.20$ & $0.95 \pm 0.38$ & 0.027 & $0.92 \pm 0.45$ & $0.91 \pm 0.30$ & 0.769 \\
\hline $\begin{array}{l}\text { Peak CK-MB (IU/L), median } \\
\left(25-75^{\text {th }} \text { percentiles) }\right.\end{array}$ & $\begin{array}{c}91 \\
(20-183)\end{array}$ & $\begin{array}{c}88 \\
(34-188)\end{array}$ & 0.565 & $\begin{array}{c}47 \\
(13-116)\end{array}$ & $\begin{array}{c}105 \\
(42-222)\end{array}$ & 0.001 \\
\hline $\begin{array}{l}\text { Interval from the onset of symptoms } \\
\text { to ER arrival (min), median } \\
\text { (25-75 th percentiles) }\end{array}$ & $\begin{array}{c}90 \\
(65-136)\end{array}$ & $\begin{array}{c}300 \\
(119-849)\end{array}$ & $<0.001$ & $\begin{array}{c}422 \\
(140-1,056)\end{array}$ & $\begin{array}{c}130 \\
(76-311)\end{array}$ & $<0.001$ \\
\hline \multicolumn{7}{|l|}{ Culprit vessel } \\
\hline Right coronary artery, n (\%) & $18(42)$ & $35(30)$ & 0.155 & $14(30)$ & $39(35)$ & 0.646 \\
\hline Left anterior descending artery, $\mathrm{n}(\%)$ & $20(47)$ & $68(58)$ & 0.191 & $25(54)$ & $63(55)$ & 0.916 \\
\hline Left circumflex artery, n (\%) & $5(12)$ & $14(12)$ & 0.953 & $7(15)$ & $12(11)$ & 0.406 \\
\hline No. of diseased vessels, mean \pm SD & $1.70 \pm 0.77$ & $1.79 \pm 0.83$ & 0.503 & $1.63 \pm 0.80$ & $1.83 \pm 0.81$ & 0.171 \\
\hline
\end{tabular}

Abbreviations see in Tables 1,2.

arrival were significantly shorter $(\mathrm{P}<0.001)$ in the sLOX-1positive ACS subgroup (median, $25^{\text {th }}$ and $75^{\text {th }}$ percentiles: 130 , 76 and $311 \mathrm{~min}$, respectively) than in the sLOX-1-negative ACS subgroup (median, $25^{\text {th }}$ and $75^{\text {th }}$ percentiles: 422,140 and $1,056 \mathrm{~min}$, respectively). The ROC curves of hs-TnT for detecting ACS, STEACS and NSTEACS in the respective sLOX-1negative subgroups, using the sLOX-1-negative non-ACS subgroups as negative references, are shown in Figures 4D-F and the diagnostic accuracy determined by these ROC curves is indicated in Table 3. The AUC values of these ROC curves for hs-TnT to detect ACS, STEACS and NSTEACS were $0.798,0.825$, and 0.764 , respectively, and the sensitivity and specificity of hs-TnT to diagnose ACS in patients with sLOX1-negative ACS were $73.9 \%$ and $83.9 \%$, respectively, at an optimal cut-off value of $0.0520 \mathrm{ng} / \mathrm{ml}$.

\section{Discussion}

The universal definition of AMI states that AMI is the diagnosis when blood levels of cardiac biomarkers, preferably troponin I or T, are increased in the clinical setting of acute myocardial ischemia, ${ }^{9}$ because cardiac troponins are specific biomarkers of myocardial damage. Highly sensitive assays for cardiac troponins have been developed ${ }^{7,8}$ and their sensitivities for diagnosing ACS are increased, so in recent years they have become the gold standard for diagnosing AMI.,10 Although some reports have indicated that hs-TnT is a sensitive enough marker of ACS, ${ }^{8}$ the sensitivity of hs-TnT to diagnose ACS in the early stage (within $3 \mathrm{~h}$ of onset) was demonstrated to be insufficient in another study. ${ }^{10}$ In the present study, serum levels of hs-TnT positively correlated with the time interval from the onset of ACS to the collection of blood samples; therefore, the insufficient sensitivity of hs-TnT in the previous study was mainly related to the kinetics of cardiac troponins during the acute stage of ACS. In contrast, the release of sLOX-1, which is regarded as a biomarker of plaque rupture or plaque instability, is expected to precede the release of myocardial damage markers, including cardiac troponins. In fact, the present study showed that sLOX-1 levels were inversely correlated with the time interval from the onset of symptoms to blood sampling. In addition, previous studies reported that sLOX-1 is superior to cardiac troponins, measured by the conventional assay, for diagnosing ACS in the early stage..$^{13,15-18}$ In the present study, we directly compared the diagnostic values of sLOX-1 and hs-TnT for ACS, and found that SLOX-1 was superior to hs-TnT during the early stage of ACS (within $3 \mathrm{~h}$ of onset).

Although increased assay sensitivity for cardiac troponins has enabled significantly earlier detection of ACS than with the conventional assay, ${ }^{7,8}$ that increase has been associated with a decrease in specificity. ${ }^{11}$ The specificity of hs-TnT to diagnose ACS appeared to be insufficient in the present study, probably because for the first time non-ACS control subjects, who had chest symptoms and ECG abnormalities, frequently included patients with myocardial damage caused by non-ACS diseases such as CSA, pulmonary thromboembolism, perimyocarditis and takotsubo cardiomyopathy, and presented with elevated serum hs-TnT levels. A recent report indicated that the hs-TnT level was frequently elevated even in patients with nonischemic heart failure. ${ }^{21}$ In real clinical settings, it is important to differentiate ACS from the other diseases associated with chest symptoms and ECG abnormalities, but this is often difficult, because both present with elevation of cardiac troponins.

Myoglobin and heart-type fatty acid-binding protein (HFABP), which are markers of myocardial damage, serve as 

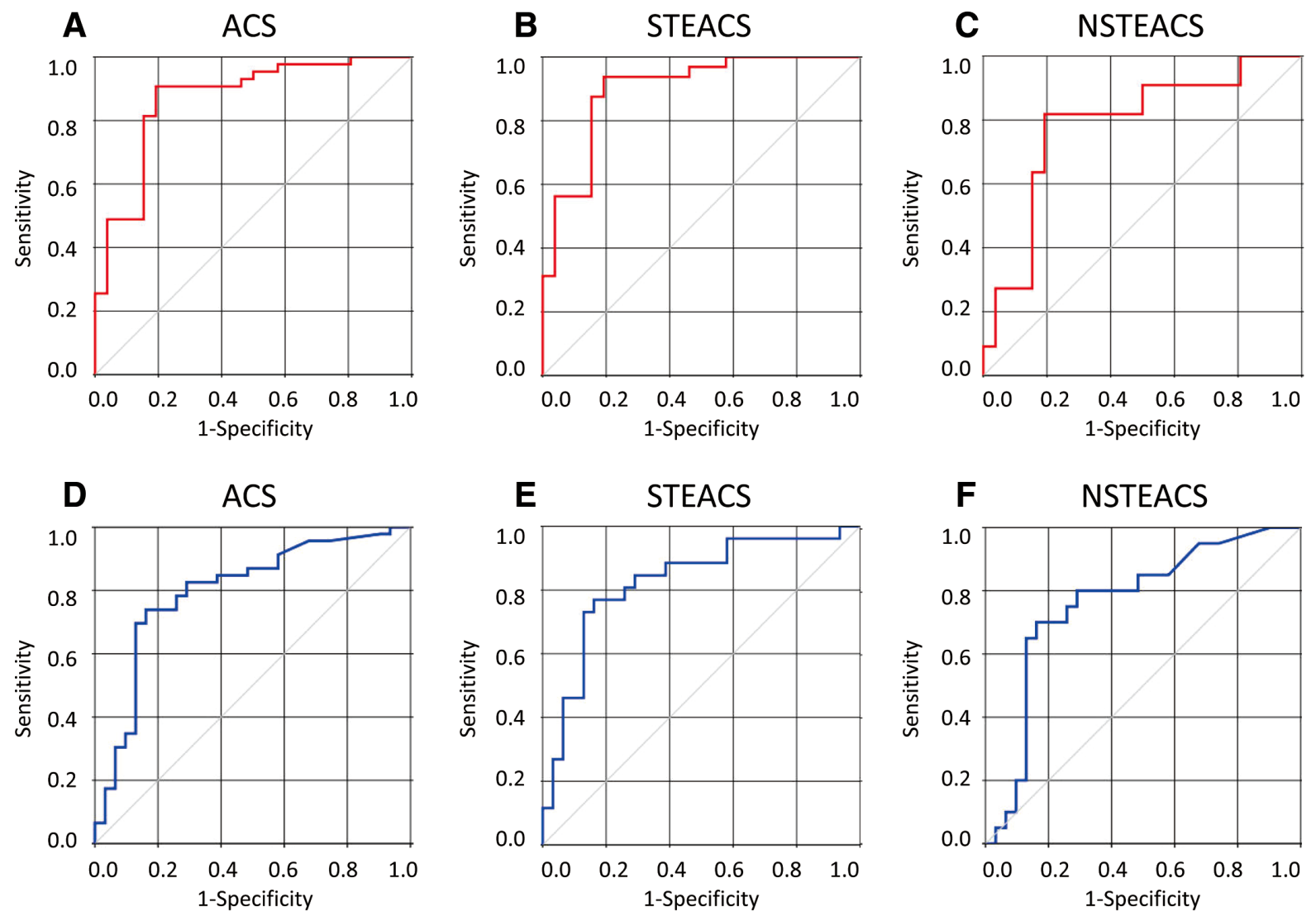

SLOX-1 $\longrightarrow$ hs-TnT

Figure 4. Diagnostic sensitivity and specificity of soluble lectin-like oxidized low-density lipoprotein receptor-1 (sLOX-1) and high-sensitivity troponin T (hs-TnT) for acute coronary syndrome (ACS) in patients with negative hs-TnT and negative sLOX-1. Receiver-operating characteristic curves for sLOX-1 (A-C) and hs-TnT (D-F) for the diagnosis of ACS (A, D), ST elevation ACS (STEACS; B, E) and non-STE ACS (NSTEACS; C, F) in patients with negative hs-TnT (A-C) and negative sLOX-1 (D-F) are shown. The area under the curve values of sLOX-1 and hs-TnT were 0.869 and 0.798 for ACS, 0.898 and 0.825 for STEACS, and 0.783 and 0.764 for NSTEACS, respectively. Negative hs-TnT or negative sLOX-1 subgroup was defined as patients with hs-TnT or sLOX-1 values less than $0.0205 \mathrm{ng} / \mathrm{ml}$ or $131.7 \mathrm{pg} / \mathrm{ml}$, respectively.

adjunct modalities for diagnosing early-stage AMI because the levels of these biomarkers usually begin to increase at $1 \mathrm{~h}$ after onset. ${ }^{22}$ Although a combination of cardiac troponins and myoglobin or $\mathrm{H}-\mathrm{FABP}$ is recommended to improve the diagnostic sensitivity for early-stage AMI, ${ }^{23}$ the diagnostic specificity may not be improved because the mechanisms involved in the elevation of cardiac troponins and myoglobin or H-FABP are almost the same. In contrast, the mechanisms involved in the elevation of SLOX-1 levels are different from those of cardiac troponins. Therefore, $\mathrm{SLOX}-1$ is expected to be an adjunctive biomarker that can be combined with troponins to differentiate ACS from other diseases with myocardial damage. In fact, a previous study has shown that SLOX-1 was able to detect ACS in cases in which TnT levels measured by a conventional assay were not increased during the acute stage, with similar sensitivity and specificity to the values determined for the whole population. ${ }^{19}$

In the present study, in which the negative reference was non-ACS patients with similar chest symptoms and ECG abnormalities in the ER, we demonstrated, for the first time, that SLOX-1 was able to detect ACS during the acute stage in cases in which the hs-TnT levels were not increased, with similar sensitivity and specificity to those in the whole population.

LOX-1, a receptor for atherogenic oxidized $\mathrm{LDL}^{12}$ and the expression of which is induced by factors related to atherogenesis and plaque vulnerability, such as proinflammatory cytokines $^{24}$, angiotensin II ${ }^{25}$ high glucose ${ }^{26}$ and oxidized LDL, ${ }^{27}$ is expressed on the surface of intimal smooth muscle cells ${ }^{28}$ and lipid-laden macrophages ${ }^{28,29}$ in advanced human atherosclerotic plaques. LOX-1, furthermore, is cleaved at the membrane-proximal extracellular domain by proteases, including a disintegrin and metalloproteinase (ADAM), ${ }^{13,14}$ which may also be associated with plaque vulnerability or rupture, thus resulting in release of sLOX-1 into the circulation. ${ }^{14}$ In experimental animal models, LOX-1 expression was closely associated with morphological plaque instability and cell apoptosis, as well as with the expression of matrix metalloproteinases and tissue factor, all of which are associated with plaque rupture and thrombus formation. ${ }^{30-32}$ Therefore, proteases with enhanced activity in ruptured or rupture-prone vulnerable plaques may be responsible for the cleavage of LOX-1 that is 
abundantly expressed in advanced coronary atherosclerotic plaques. Taken together, the evidence points to sLOX-1 being a biomarker of plaque rupture or plaque instability.

The results of the present study clearly demonstrate that plasma levels of sLOX-1 are useful for diagnosing ACS in combination with hs-TnT. Earlier elevation of sLOX-1 allowed us to diagnose ACS in the early stage, which was unable to be diagnosed by hs-TnT alone. On the other hand, neither hs-TnT nor SLOX-1 had sufficient diagnostic specificity for ACS in this cohort, because the negative control subjects included many patients with CSA, arrhythmia, pulmonary thromboembolism, perimyocarditis and takotsubo cardiomyopathy, which also showed elevated hs-TnT levels.

Elevated sLOX-1 levels were also observed in the control subjects, probably because sLOX-1 may also be released into the circulation in certain unknown cases other than coronary plaque rupture or instability. It may be speculated that SLOX1 is produced by some types of coronary vasospasm, thrombus formation in the pulmonary artery, and reduced cardiac function. ${ }^{33}$ Further investigations are necessary to clarify that point.

Plasma sLOX-1 levels were significantly higher in STEACS than in NSTEACS patients, probably because the time intervals from the onset of chest symptoms the ER arrival were significantly shorter in the STEACS than in the NSTEACS group in the present study. In addition, differences in plaque characteristics, such as rupture or erosion, may also have affected the difference in SLOX-1 levels between the STEACS and NSTEACS groups. Plasma SLOX-1 levels were higher in patients with diabetes and a smoking habit than in those without, probably because high glucose levels induce the expression of LOX-1, as previously shown by an in vitro study, ${ }^{26}$ and smoking affects plaque vulnerability by inducing oxidative stress and inflammation. ${ }^{34}$ Serum peak CK-MB values were higher in patients with a sLOX-1 value $\geq 131.7 \mathrm{pg} / \mathrm{ml}$ in the ER than in those with a value $<131.7 \mathrm{pg} / \mathrm{ml}$, which means the sLOX-1 values in the ER probably indicated the severity of ACS. A recent pilot study has shown that sLOX-1 predicted prognosis, such as recurrence or death, in ACS patients. ${ }^{35}$ Prognoses of ACS patients should be investigated in larger patient samples in the future. Multidetector row computed tomography ${ }^{36}$ and intravascular ultrasound ${ }^{37}$ have been used to detect patients with vulnerable plaques. Measuring SLOX-1 may be a less invasive tool for the same purpose. In addition, sLOX-1 could be used to evaluate the therapeutic effects, such as administration of statins ${ }^{38}$ or angiotensin II receptor blockers, ${ }^{39}$ and body weight reduction, ${ }^{40}$ because LOX-1 expression has been shown to be reduced by these interventions. However, in the present study plasma levels of sLOX-1 were comparable between patients with prehospital use of ACEI/ARB or statins and those without. In any case, for early diagnosis of ACS in the ER, it would be desirable for rapid SLOX-1 measurement kits to become commercially available in the future.

In conclusion, using SLOX-1, a biomarker of plaque rupture or vulnerability, or hs-TnT, a biomarker of myocardial damage, alone appears to be insufficient for diagnosing ACS in the real clinical setting. Therefore, the diagnostic accuracy for ACS would be improved by using a combination of sLOX-1 and hs-TnT. However, the limitations of the present study, including its relatively small sample size, indicate that the present findings should be confirmed by multicenter studies with larger sample sizes. Atherosclerotic disease other than coronary artery diseases, such as ischemic stroke, ${ }^{41}$ aortic atherosclerosis, ${ }^{24}$ and peripheral arteriosclerosis obliterans, probably affect the levels of sLOX-1 because the expression of LOX-1 is not specific for atherosclerosis of coronary arteries. Although some reports have demonstrated a relationship between plaque rupture and SLOX-1 in in-vitro experiments, there have been no reports that indicate that relationship in vivo, so further studies are necessary to clarify the mechanisms of sLOX-1 elevation.

\section{Acknowledgments}

We thank the medical and nursing staff of Nippon Medical School Chiba Hokusoh Hospital, and the patients for participating in this study.

This study was supported, in part, by a research grant from the Diagnostics Division, Shionogi \& Co Ltd, Osaka, Japan.

\section{References}

1. Lee TH, Goldman L. Serum enzyme assays in the diagnosis of acute myocardial infarction: Recommendations based on a quantitative analysis. Ann Intern Med 1986; 105: 221-233.

2. Antman EM, Grudzien C, Sacks DB. Evaluation of a rapid bedside assay for detection of serum cardiac troponin T. JAMA 1995; 273: $1279-1282$.

3. Ohman EM, Armstrong PW, Christenson RH, Granger CB, Katus $\mathrm{HA}, \mathrm{Hamm} \mathrm{CW}$, et al. Cardiac troponin T levels for risk stratification in acute myocardial ischemia: GUSTO IIA Investigators. $N$ Engl $J$ Med 1996; 335: 1333-1341.

4. Antman EM, Tanasijevic MJ, Thompson B, Schactman M, McCabe $\mathrm{CH}$, Cannon $\mathrm{CP}$, et al. Cardiac-specific troponin I levels to predict the risk of mortality in patients with acute coronary syndromes. $N \mathrm{Engl}$ J Med 1996; 335: 1342-1349.

5. Hamm CW, Goldmann BU, Heeschen C, Kreymann G, Berger J, Meinertz T. Emergency room triage of patients with acute chest pain by means of rapid testing for cardiac troponin T or troponin I. $N$ Engl JMed 1997; 337: 1648-1653.

6. Antman EM, Sacks DB, Rifai N, McCabe CH, Cannon CP, Braunwald E. Time to positivity of a rapid bedside assay for cardiacspecific troponin $\mathrm{T}$ predicts prognosis in acute coronary syndromes: A Thrombolysis in Myocardial Infarction (TIMI) 11A substudy. $J$ Am Coll Cardiol 1998; 31: 326-330.

7. Keller T, Zeller T, Peetz D, Tzikas S, Roth A, Czyz E, et al. Sensitive troponin I assay in early diagnosis of acute myocardial infarction. N Engl J Med 2009; 361: 868-877.

8. Reichlin T, Hochholzer W, Bassetti S, Steuer S, Stelzig C, Hartwiger $\mathrm{S}$, et al. Early diagnosis of myocardial infarction with sensitive cardiac troponin assays. $N$ Engl J Med 2009; 361: 858-867.

9. Thygesen K, Alpert JS, White HD, Jaffe AS, Apple FS, Galvani M, et al. Universal definition of myocardial infarction. Circulation 2007; 116: $2634-2653$.

10. Giannitsis E, Kurz K, Hallermayer K, Jarausch J, Jaffe AS, Katus HA. Analytical validation of a high-sensitivity cardiac troponin T assay. Clin Chem 2010; 56: 254-261.

11. Morrow DA. Clinical application of sensitive troponin assays. $N$ Engl J Med 2009; 361: 913-915.

12. Sawamura T, Kume N, Aoyama T, Moriwaki H, Hoshikawa H, Aiba Y, et al. An endothelial receptor for oxidized low-density lipoprotein. Nature 1997; 386: 73-77.

13. Mitsuoka H, Kume N, Hayashida K, Inui-Hayashiada A, Aramaki Y, Toyohara M, et al. Interleukin 18 stimulates release of soluble lectinlike oxidized LDL receptor-1 (sLOX-1). Atherosclerosis 2009; 202: 176-182.

14. Murase T, Kume N, Kataoka H, Minami M, Sawamura T, Masaki T, et al. Identification of soluble forms of lectin-like oxidized LDL receptor-1. Arterioscler Thromb Vasc Biol 2000; 20: 715-720.

15. Ueda A, Kume N, Hayashida K, Inui-Hayashida A, Asai M, Kita T, et al. ELISA for soluble form of lectin-like oxidized LDL receptor-1, a novel marker of acute coronary syndrome. Clin Chem 2006; 52: $1210-1211$.

16. Hayashida K, Kume N, Murase T, Minami M, Nakagawa D, Inada $\mathrm{T}$, et al. Serum soluble lectin-like oxidized low-density lipoprotein receptor-1 levels are elevated in acute coronary syndrome: A novel marker for early diagnosis. Circulation 2005; 112: 812-818.

17. Nakamura M, Ohta H, Kume N, Hayashida K, Tanaka M, Mitsuoka $\mathrm{H}$, et al. Generation of monoclonal antibodies against a soluble form of lectin-like oxidized low-density lipoprotein receptor-1 and development of a sensitive chemiluminescent enzyme immunoassay. J Pharm Biomed Anal 2010; 51: 158-163.

18. Kobayashi N, Hata N, Kume N, Seino Y, Inami T, Yokoyama S, et al. Soluble lectin-like oxidized low-density lipoprotein receptor-1 as an early biomarker for ST elevation myocardial infarction. Circ J 2011; 
75: $1433-1439$.

19. Kume N, Mitsuoka H, Hayashida K, Tanaka M, Kominami G, Kita T. Soluble lectin-like oxidized LDL receptor-1 (sLOX-1) as a sensitive and specific biomarker for acute coronary syndrome: Comparison with other biomarkers. J Cardiol 2010; 56: 159-165.

20. Mingels A, Jacobs L, Michielsen E, Swaanenburg J, Wodzig W, van Dieijen-Visser M. Reference population and marathon runner sera assessed by highly sensitive cardiac troponin $\mathrm{T}$ and commercial cardiac troponin T and I assays. Clin Chem 2009; 55: 101-108.

21. Kawahara C, Tsutamoto T, Nishiyama K, Yamaji M, Sakai H, Fujii $\mathrm{M}$, et al. Prognostic role of high-sensitivity cardiac troponin $\mathrm{T}$ in patients with nonischemic dilated cardiomyopathy. Circ J 2011; 75: 656-661.

22. Seino Y, Ogata K, Takano T, Ishii J, Hishida H, Morita H, et al. Use of a whole blood rapid panel test for heart-type fatty acid-binding protein in patients with acute chest pain: Comparison with rapid troponin T and myoglobin tests. Am J Med 2003; 115: 185-190.

23. Jurlander B, Clemmensen P, Wagner GS, Grande P. Very early diagnosis and risk stratification of patients admitted with suspected acute myocardial infarction by the combined evaluation of a single serum value of cardiac troponin-T, myoglobin, and creatine kinase MB(mass). Eur Heart J 2000; 21: 382-389.

24. Kume N, Murase T, Moriwaki H, Aoyama T, Sawamura T, Masaki $\mathrm{T}$, et al. Inducible expression of lectin-like oxidized LDL receptor-1 in vascular endothelial cells. Circ Res 1998; 83: 322-327.

25. Li DY, Zhang YC, Philips MI, Sawamura T, Mehta JL. Upregulation of endothelial receptor for oxidized low-density lipoprotein (LOX-1) in cultured human coronary artery endothelial cells by angiotensin II type 1 receptor activation. Circ Res 1999; 84: 1043-1049.

26. Li L, Sawamura T, Renier G. Glucose enhances endothelial LOX-1 expression: role for LOX-1 in glucose-induced human monocyte adhesion to endothelium. Diabetes 2003; 52: 1843-1850.

27. Kataoka H, Kume N, Miyamoto S, Minami M, Morimoto M, Hayashida K, et al. Oxidized LDL modulates Bax/Bcl-2 through the lectinlike Ox-LDL receptor-1 in vascular smooth muscle cells. Arterioscler Thromb Vasc Biol 2001; 21: 955-960.

28. Moriwaki H, Kume N, Kataoka H, Murase T, Nishi E, Sawamura T, et al. Expression of lectin-like oxidized low density lipoprotein receptor-1 in human and murine macrophages: Upregulated expression by TNF-alpha. FEBS Lett 1998; 440: 29-32.

29. Kataoka H, Kume N, Miyamoto S, Minami M, Moriwaki H, Murase $\mathrm{T}$, et al. Expression of lectinlike oxidized low-density lipoprotein receptor-1 in human atherosclerotic lesions. Circulation 1999; 99: $3110-3117$.

30. Ishino S, Mukai T, Kume N, Asano D, Ogawa M, Kuge Y, et al.
Lectin-like oxidized LDL receptor-1 (LOX-1) expression is associated with atherosclerotic plaque instability: Analysis in hypercholesterolemic rabbits. Atherosclerosis 2007; 195: 48-56.

31. Kuge Y, Kume N, Ishino S, Takai N, Ogawa Y, Mukai T, et al. Prominent lectin-like oxidized low density lipoprotein (LDL) receptor-1 (LOX-1) expression in atherosclerotic lesions is associated with tissue factor expression and apoptosis in hypercholesterolemic rabbits. Biol Pharm Bull 2008; 31: 1475-1482.

32. Ishino S, Mukai T, Kuge Y, Kume N, Ogawa M, Takai N, et al. Targeting of lectinlike oxidized low-density lipoprotein receptor 1 (LOX-1) with 99mTc-labeled anti-LOX-1 antibody: Potential agent for imaging of vulnerable plaque. J Nucl Med 2008; 49: 1677-1685.

33. Takaya T, Wada H, Morimoto T, Sunagawa Y, Kawamura T, Takanabe-Mori R, et al. Left ventricular expression of lectin-like oxidized low-density lipoprotein receptor-1 in failing rat hearts. Circ J 2010; 74: 723-729.

34. Yanbaeva DG, Dentener MA, Creutzberg EC, Wesseling G, Wouters EF. Systemic effects of smoking. Chest 2007; 131: 1557-1566.

35. Kume N, Mitsuoka H, Hayashida K, Tanaka M, Kita T. Soluble lectin-like oxidized low-density lipoprotein receptor-1 predicts prognosis after acute coronary syndrome: A pilot study. Circ J 2010; 74: $1399-1404$

36. Higashi M. Noninvasive assessment of coronary plaque using multidetector row computed tomography. Circ J 2011; 75: 1522-1528.

37. Ando H, Amano T, Matsubara T, Uetani T, Nanki M, Marui N, et al. Comparison of tissue characteristics between acute coronary syndrome and stable angina pectoris: An integrated backscatter intravascular ultrasound analysis of culprit and non-culprit lesions. Circ J 2011; 75: 383-390.

38. Matsumoto T, Fujita M, Sawamura T, Kakino A, Sato Y, Fujita Y, et al. Pitavastatin reduces lectin-like oxidized low-density lipoprotein receptor-1 ligands in hypercholesterolemic humans. Lipids 2010; 45: 329-335.

39. Morawietz H, Erbs S, Holtz J, Schubert A, Krekler M, Goettsch W, et al. Endothelial protection, AT1 blockade and cholesterol-dependent oxidative stress: The EPAS trial. Circulation 2006; 114: I296I301.

40. Nomata Y, Kume N, Sasai H, Katayama Y, Nakata Y, Okura T, et al. Weight reduction can decrease circulating soluble lectin-like oxidized low-density lipoprotein receptor-1 levels in overweight middle-aged men. Metabolism 2009; 58: 1209-1214.

41. Inoue N, Okamura T, Kokubo Y, Fujita Y, Sato Y, Nakanishi M, et al. LOX index, a novel predictive biochemical marker for coronary heart disease and stroke. Clin Chem 2010; 56: 550-558. 